\title{
A Game Model for Dynamic Competition of Advanced Manufacturing Industry Cluster
}

\author{
Qiang Feng \\ School of Management \\ Donghua University \\ Shanghai, China \\ School of Management \\ Ningbo Institute of Technology, Zhejiang University \\ Ningbo, China \\ nitfq@163.com
}

\begin{abstract}
Manufacturing is the main source of the pillar industries of national economy and national income. In the globalization environment, on the one hand, the competition in manufacturing has been from the market competition to the competition of industrial cluster evolution; On the other hand, the development of advanced manufacturing industry become the development direction of manufacturing industry in the future. This paper first discusses the dynamic competition for manufacturing, further defined the manufacturing strategy of main body in a dynamic environment. Also puts forward the advanced manufacturing dynamic game model of competition. Finally, there is a analysis of the advanced manufacturing cluster strategy, which using the dynamic game model. The conclusion of this paper provides an analysis of manufacturing methods of industrial competition and cooperation relationship. It provides a reference basis for related departments in accordance with the current situation of the development of manufacturing and the adjustment of industrial policies.
\end{abstract}

Keywords- Game Model; Dynamic Competition; Advanced Manufacturing; Industrial competitiveness;Industry Cluster

\section{INTRODUCTION}

With the change of the international competitive environment, and the change of the competition intensity between enterprises, the companies and scholars have a new understanding to the theory of enterprise competition. Since the early $1990 \mathrm{~s}$, on the basis of summarizing the competition theory, Western management scholars is put forward and developed the theory of dynamic competition. In 1994, Richard D'Aveni in the chief editor of "the Hyper-Competition: Managing the Dynamics of Strategic Maneuvering, puts forward the concept of "super Competition "[1]. In 1996, Day, George S., Reibstein, David J. and Gunther, Robert E. in the book of "Stan coedited the Wharton on Dynamic Competitive Strategy" summed up this competition phenomenon as "Dynamic competition". It makes a detailed study of Dynamic competition Strategy.

In a dynamic environment, with the intensification of competition, enterprise's every move, can cause the response of competitors quickly accordingly. Namely from dynamic game, static game into competitive advantage continuously by rivals to imitate and transcendence, makes any competitive advantage presents the characteristics of transient and temporary. As the change of time, one of the old competitive advantage would be likely to dissipate or destroyed by active, a new edge initiation. In the process of their growth continuously, if enterprise creates new competitive advantages instead of competitive advantage of the old, it will form the dynamic competitive advantage, in order to gain sustainable competitive advantage as a whole. Therefore, it should be able to effectively cope with changes in the environment, grasp the opportunity and dissolve the risk, and can continuously in the process to create new competitive advantage, if the enterprise is to achieve sustained growth. The whole competitive advantage of enterprises becomes into a dynamic system. In order to gain sustainable competitive advantage, the development of the whole competitive advantage is forming a continuous wave continued growth trajectory(Fig .1)

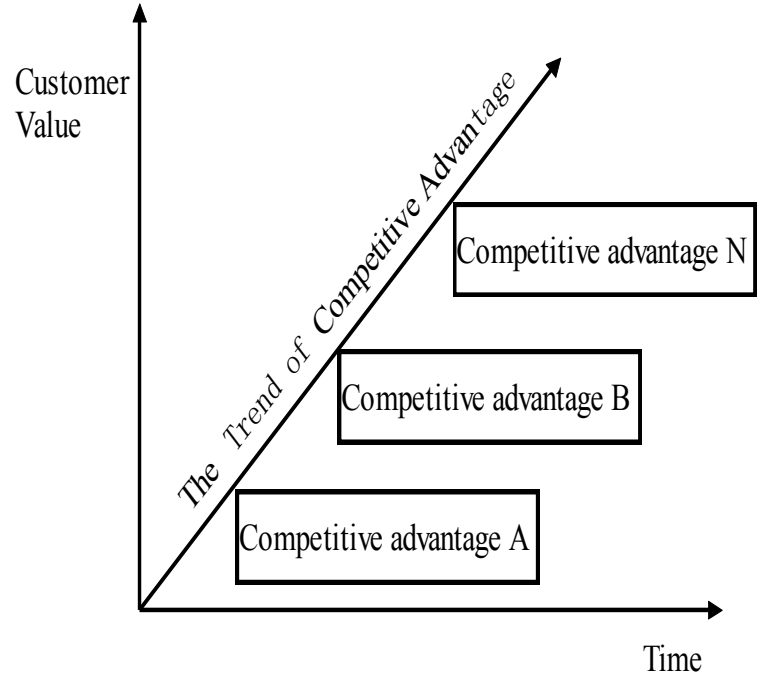

Figure 1. The Development Trend of Competitive Advantage 


\section{THE MAIN BODY IN THE STRATEGY OF DYNAMIC COMPETITION}

Must clear the connotation of the advanced manufacturing industry, if we Want to develop advanced manufacturing. If the content is too broad, so in the process of the development of advanced manufacturing industry, inevitably lead to resource allocation unable to concentrate, is the result of the pursuit of a lot, will sacrifice the development of the manufacturing efficiency. If content is too narrow, and cause of industrial structure is not reasonable. It should be from ultra micro, meso and micro three-dimensional perspective to theoretical generalization of advanced manufacturing, which combined with the development of the manufacturing industry in the international trend and characteristics of the development of the manufacturing industry in the advanced countries.

At present, in terms of the advanced manufacturing industry, there are mainly two aspects. one is the forefront of advanced technology of manufacturing can be referred to as advanced manufacturing industry. The others is to use advanced technology upgrading and transformation of the traditional manufacturing can delimit to within the ranks of advanced manufacturing. With less of the former view of scholars, such as peng benhong(2009), namely the use of advanced manufacturing technology and advanced equipment, modern management methods and manufacturing mode, high technology content of manufacturing [2]. Li Lianshui, Du Zhanyuan (2005) for the first time will pay attention to scientific and technological innovation in manufacturing are expressed as "new manufacturing", namely, rely on scientific and technological innovation, reduce energy consumption, reduce environmental pollution, increase employment, improve the economic benefit and promote competition ability, to realize the sustainable development of manufacturing industry, and establish the evaluation index system of economy, technology and environment aspects of [3]. Qin Shijun (2004) is constantly absorbing advanced manufacturing, electronic information, computer and other high-tech achievements and used to develop the design, manufacture and service process management, obtained very good economic, social and market effect of the floorboard of the manufacturing industry. More and more scholars believe that, in addition to advanced manufacturing technology factors such as the most advanced industry, should also include some characteristics of traditional manufacturing part of the advanced manufacturing[4].Chen baomin (2006) advanced manufacturing industry is constantly absorbing advanced technology and advanced management mode and modern management technology, integrated application of the advanced manufacturing technology to the floorboard of the whole manufacturing process, including not only as the new and high technology industries, also includes the advanced manufacturing technology and the application of advanced manufacturing mode has become the leading industry that part of the traditional manufacturing [5]. Li hui, Cui Qianqian, Sun keqiang(2008) advanced manufacturing is defined as: constantly absorbing advanced technology and advanced management methods and advanced development model, the integrated use of the advanced manufacturing technology to the production process of manufacturing, including not only new and high technology industries, also including the application of advanced technology and management methods of a part of the traditional manufacturing [6].

These explanations are reasonable, but it is not comprehensive and accurate. First, advanced manufacturing industry is inseparable from the advanced technology, but only the use of advanced technology, or only from the advanced technology to define, to reveal the connotation of the advanced manufacturing industry, also can't define a advanced manufacturing industry and advanced technology as the symbol of the difference between a new and high technology industries. In fact, the traditional manufacturing industry is the pursuit of technical progress. Second, advanced manufacturing industry is not only limited to the production process, should also include the whole process of prenatal and postnatal, but it is not enough to explain the advanced manufacturing industry is a new mode of production. Finally, advanced manufacturing these explanations are regarded as a closed system, ignored the modern networked marketing system and extensive connection between enterprises.

The dynamic competitive advantage is an enterprise within the industry to obtain competitive advantage in the changing market environment. The growth of the industry status is subject to the strength of each enterprise's competitive advantage in the industry and their sustainability. The continuous growth of the industry must be based on the creation of competitive advantage and sustainable. If enterprises can continuously create and sustain competitive advantage, it can continue to grow.

Under the condition of static competition, the enterprise strategic choice scope of smaller, cope with the competition way limited the launch of new products, entering new markets such as narrow range. Dynamic competition of enterprise is not simply to attacks or competitors' products, it has numerous forms of means of competition and competition to choose from. Karnani and Wernerfelt (1985) of multipoint competition model describes the competitors at the same time between multiple according to regional markets and business competition situation [7]. In multipoint competition, a marketing or business field companies may choose to attack on another market or business region hit back. In multiple industries and more competition in the market for the enterprise strategic choice, also increases the complexity of the decision. D'Aveni (1994) put forward the dynamic competition model describes the process of industry evolution, this evolution is through a series of its called "dynamic strategic interaction" attack and counter attack [1]. His model tested four dynamic strategic interaction in the field of competition, every field based on the different competitive advantage. Once businesses attack and counter attack in one region, they will seek inhibition, damage, or totally destroy a competitor's competitive advantage.

Under the condition of static competition, the development of technology and customer demand is predictable, stable and long time. Therefore, the enterprise often pursues the product center strategy. The strategy formulation and implementation of revolve is around specific products, and the focus is on the improvement of the existing products. Maintain competitive advantage 
simply means that, in the established goals, environment and resources available to case, enterprise for competitors to imitate, alienation and alternative actions to improve and upgrade the existing products. As the competition between modern enterprises evolution for the dynamic competition, product center strategy is more and more show its not adapt. Because the product is simply the market drivers and technical approach for integration, product centered perspective can explain the current competitive advantage, but can't explain how to create competitive advantage in the future. Product center strategy of dynamic competition does not adapt to enable people to turn your attention to the key driver behind the product competition, the core competencies. Core competence is the enterprise has the unique combination of resources, technology, knowledge and skills, it is the foundation of the enterprise all final products and services, and enterprises can easily develop new market. C.k. Prahalad (1990), and other scholars pointed out that the core competence has specificity, difficult to imitation, and many other features [8].

It seems that in dynamic competition, the appearance of the product competition is the competition between the enterprises and form. The core ability of competition is the real subject of competition. It is the basic driving factor of dynamic competition. Enterprise is necessary at the center of the strategic ability to shift from product center to center, you shift your focus from the improvement of the product, to focus on the creation of the core competence and ascend.

\section{THE CONSTRUCTION OF A GAME MODEL}

\section{A. Basic Assumptions}

Regional subject on the basis of comparing their competitive advantage, cooperation and non-cooperation dynamic competition has two options. The problem of regional cooperation in the competition or not, in fact, is the problem region of preference and choice, or is the game between the regional body. Then by comparison with the $i$ and $j$ region can carry on careful analysis.

Hypothesis 1: Analysis is limited to two region within a country, they are not subject to any other region, the influence of the two with the interests of the boundary of the rational "economic man" group combination.

Hypothesis 2: Two regional not caused by a different advantage, cooperation according to the relative competitive advantage in proportion to reduce cost of industrial development, industrial benefit distribution related to the relative competitive advantage.

Hypothesis 3: Industry competitive advantage factors influence depends on industry competition project types.

Hypothesis 4: A single regional expansion of industrial scale, will produce positive or negative to another region of externalities.

\section{B. Maintaining the Game Strategy Analysis}

1) under the obvious advantages of competition game

Industrial scale expansion should fully consider the condition of industrial development. When two regions have the advantage of six to one, in the process of game, if advantages and disadvantages, choose cooperation so advantage benefited 23, underdog due to positive externalities gain 5. If choose not to cooperation, advantage may adopt off shoring obstruct positive externalities method instead gain 25 , underdog lose 15 . If advantage to choose cooperation transfer part of the external benefit cut to 20 , while underdog choose not to receive part of the cooperation positive externalities coming from the advantage side effect, makes up for the loss of gain scale expansion of 1 . If advantage parties choose cooperation is 25 , enjoy all the benefits of a project to bring the industry at this point, the underdog choose cooperation profit to 2 . From the top, in the case of absolute obvious advantages, the advantages of party tend to choose not to cooperate. Maximized itself underdog only choose cooperation get a small amount of interest, if choose not to cooperate, the loss scale expansion. E combination is the Nash equilibrium of choice in this case.

2) the advantage is not obvious under the competition game

In industrial scale expansion if the comparative advantage is not obvious between the two regions, regional principal goal will take the most conducive to the development of the regional economic strategy, but may produce differences between expected benefits and practical benefits. Can be divided into the following investigation table of A, B, C, D four strategy combinations.

A strategy combinations: $\mathrm{I}$ region and $\mathrm{j}$ region all choose cooperation scale expansion strategy, both sides benefit from 15. Overall, is conducive to the optimal combination of the whole social and economic development, realize the pareto optimality, reasonable but not it is a game, because there is a good D combination of reasons. Region in the I (or $\mathrm{j}$ region) under the condition of invariable strategy, $\mathrm{j}$ region (or $\mathrm{i}$ region) $\mathrm{I}$ have a choice not cooperation. Because in a choice under the premise of cooperation, both share the cooperation not spending increases the scale expansion of 2 . The other party chooses not to cooperation can still be won in the best interests of 18 (20-2), more than choosing cooperation benefits received. According to the analysis of regional subject rational behavior as long as there is a certain probability choose not to believe that other party, one party cooperation, it also has chosen not to cooperation motivation. Strategy combination A itself has inherent instability, it is easy to $\mathrm{D}$ to strategy combinations.

Strategy combination B and C: A regional selection, another region chooses not to cooperation. If $\mathrm{j}$ region choice remains the same, I region by the region subject to choose not to cooperation the profit is 18. Compared with other combinations, it is the optimal choice, not the power to change. But in determining the region without cooperation, $\mathrm{I} \mathrm{j}$ region in order to increase the benefit of this region is also go to cooperation. This can increase the interest 2 , and then by the combination of $\mathrm{B}$ to $\mathrm{D}$ combination. In the same way, also can be combined deduce $\mathrm{C}$ to $\mathrm{D}$ combination, combination strategy $\mathrm{B}, \mathrm{C}$ are inherent instability.

Strategy combination D: Two main region are made not cooperative decision. Assuming I regional strategy is kept constant, $\mathrm{j}$ region did not transform selection of economic incentives. Because once it transform for cooperation, and finally the combination strategy will only make this region loss of 2 , to say the strategy combination $\mathrm{D}$ is the combination of relatively stable form. 
TABLE I. THE SCALE EXPANSION GAME STRATEGY OF TWO REGIONS IN INDUSTRIAL SCALE RXPANSION

\begin{tabular}{|c|c|c|c|}
\hline $\begin{array}{c}\text { Comparative } \\
\text { Advantage }\end{array}$ & \multicolumn{3}{|c|}{ Game Strategy } \\
\hline \multirow{3}{*}{$\begin{array}{c}\text { Industry } \\
\text { Competitiveness is } \\
\text { Similar of the } \\
\text { Region I and } \mathbf{J}\end{array}$} & $\begin{array}{c}\text { Different } \\
\text { Regions } \\
\end{array}$ & Cooperation & $\begin{array}{c}\text { Don't } \\
\text { Cooperate }\end{array}$ \\
\hline & Cooperation & $A(15,15)$ & $C(3,18)$ \\
\hline & $\begin{array}{c}\text { Don't } \\
\text { Cooperate }\end{array}$ & $B(18,3)$ & $D(5,5)$ \\
\hline \multirow{3}{*}{$\begin{array}{l}\text { Industry } \\
\text { Competitiveness I } \\
\text { region is Greater } \\
\text { than J Region }\end{array}$} & $\begin{array}{c}\text { Different } \\
\text { Regions }\end{array}$ & Cooperation & $\begin{array}{c}\text { Don't } \\
\text { Cooperate }\end{array}$ \\
\hline & Cooperation & $(23,5)$ & $(23,5)$ \\
\hline & $\begin{array}{c}\text { Don't } \\
\text { Cooperate }\end{array}$ & $E(25,2)$ & $E(25,2)$ \\
\hline \multirow{3}{*}{$\begin{array}{l}\text { Industry } \\
\text { Competitiveness J } \\
\text { region is Greater } \\
\text { than I Region }\end{array}$} & $\begin{array}{c}\text { Different } \\
\text { Regions }\end{array}$ & Cooperation & $\begin{array}{c}\text { Don't } \\
\text { Cooperate }\end{array}$ \\
\hline & Cooperation & $(5,23)$ & $(5,23)$ \\
\hline & $\begin{array}{c}\text { Don't } \\
\text { Cooperate }\end{array}$ & $(1,20)$ & $(1,20)$ \\
\hline
\end{tabular}

\section{MAIN CONCLUSIONS AND COUNTERMEASURES}

\section{1) Main conclusions}

Comprehensive the above analysis, it can be concluded that the general conclusions. In the process of concurrence of industrial scale expansion, in the case of obvious advantages, the advantages will generally choose not cooperation (specific circumstances, of course, want to consider other factors), underdog best choice for cooperation. In the case of advantage is not obvious, in pursuit of their respective regional interests maximization goal, will choose not to cooperate. In the "prisoner's dilemma", if it was A one-off game, from the combination of $\mathrm{A}, \mathrm{B}, \mathrm{C}$ to $\mathrm{D}$ combination is reasonable in game. To the nature and combination $\mathrm{D}$ non-cooperative game in no way to form a binding agreement or mechanism, the game can only be the result of the cooperation. This for us to solve the "prisoner's dilemma" offers some train of thought.

\section{2) countermeasures}

There are four aspects of advanced manufacturing industry cluster's dynamic competition strategy.

The instability of combination of A given game, each game subject should enhance the ability of game analysis to each other, fully realized the anticipated effect and future effect, expected benefits, and there is A deviation between practical benefits in the future. If a game analysis of each subject can be used to treat their own scale expansion strategy choice. when there are also other subject's strategy choice, it should choose relatively the subprime, relative to the optimal combination of the whole society.

Each region should be set up with industrial scale expansion corresponding operation rules and coordination mechanism. Such as the regional cooperation mechanism, regional coordination mechanism, the industry association (provide information exchange, intermediary services, etc.), full of information transmission and communication, coordination of interests contradiction and conflict.

The central government on the regional industrial scale expansion should intensify examination and supervision, put an end to do not conform to the requirements of the regional interests of the industry in the region of the inappropriate scale expansion. At the same time, cooperation promotes the regional economic. It makes the interests of the parties reach an acceptable scheme. Set out from the actual situation of the regional economy, it should establish regional interests distribution and compensation mechanism, and narrow the regional economic development gap between.

Take the market together with the government behavior mode and operation mechanism on industrial scale expansion. In giving full play to the market mechanism to promote the production elements to the benefit of a good regional flow at the same time, strengthen the government's macroeconomic regulation and control, use of fiscal policy to support the best industrial project in the best place to develop scale expansion. But for those who disregard the interests of the whole industry scale expansion behavior take punitive measures, so as to reduce the blindness of industrial cluster scale expansion.

\section{REFERENCES}

[1] D'Aveni.Hypercompetition: "Managing the Dynamics of Strategic Maneuvering, "M.New York:Free Press.1994.

[2] Peng-benhong, "The research of co-evolution on Modern logistics industry and advanced manufacturing,"J. China Soft Science,2009 (s1),pp:149-153.

[3] Li-lianshui,Du-zhanyuan, "The new manufacturing concept, connotation and significance,'J. Science research,2005(2),pp:184187.

[4] Qin-shijun, "The world's advanced manufacturing industry development situation,'J. East China science and technology,2004 (12),pp:16-18.

[5] Chen-baoming, The world's advanced manufacturing innovation and the development tendency and its revelation,J. The channel technology and industry,2006(5),pp:34-38.

[6] Li-hui,Cui-qianqian and Sun-keqiang, "The study of Yangtze river delta advanced manufacturing industry development,"J.2008(4),pp: 52-60.

[7] Karnani,A.and Wernerfelt,B. "Multiple point competition, "J. Strategic Management Journal.1985(6),pp:87-96.

[8] Prahalad C.,and Hamel G.. "The Core Competence of the Corporation, "J.Harvard Business Review, May-June,1990,pp:7991.

[9] Adam M. Brandenburger and Barry J. Nalebuff. “Coopetition, ”M. New York: Doubleday,1996.

[10] Porter. M.E. "Clusters and New Economics of Competition, "J.Harvard Business Review,1998,(11).

[11] Yiannis Kamarianakis,Vagelis Kaslis. "Competitioncomplementarity relationships between Greek Regional Economies, "ERSA Conference Papers,2005.

[12] Su-fanglin,Hou-xiaobo, "Based on D-S model of the central plains urban agglomeration industry development, "J. Journal of Hunan College of Finance and Economics.10(2010),pp:89-92.

[13] Li-hui,Cui-qianqian,Sun-keqiang, "The study of Yangtze river delta advanced manufacturing industry development, "J.2008(4), pp:52-60

[14] Tang jian and Yang Han-bing, "Research on Development Mechanism and Path of Enterprise Competitiveness from the Perspective of Evolutionary Game, ” J. Journal of yunnan finance and economics university.2012(1),pp:108-114 